\title{
CHARACTERISTICS OF THE HANDBALL GAME AT THE SENIOR'S LEVEL IN THE CURRENT TIME PERIOD
}

\author{
Mihai TIMOFTE ${ }^{1}$ \\ Florin LEUCIUC ${ }^{2}$ \\ ${ }^{I}$ Secondary School Osoi, Romania \\ ${ }^{2}$ Stefancel Mare University of Suceava, Romania
}

\begin{abstract}
In order to properly prepare a team, it is necessary to act physically, technically, tactically and motivationally to learn to analyze the situations of the game and to solve them in complex conditions. Achieving sporting performance is based on the implementation of an optimal game strategy and concept, from which game models are developed and training models are tailored according to the potential of the team. In order to achieve performance in handball, efficiency is an essential part, and this largely depends on the handball player's experience and his ability to concentrate on key moments of matches. The increasing number of scored goals is a consequence of the increasing number of attacks, the reduction of the duration of the attack and the marking of goals on the counterattack; all these rely on the principles of dynamic and fast pace game. To meet these requirements in the current handball, players have to face the new physical, technical and tactical demands required by the fast and sustained rhythm of the game. The difference in game is done by individual or small group actions and where decisional speed is essential in gaining efficiency and performance, so workouts must focus on: improving the technique and individual tactics; creating the ability to solve the 1-to1 relationship in attack and defence; compliance with the established tactical plan; to improve collaboration on small groups (2 to 2, 3 to 3 ).
\end{abstract}

Key words: handball, preparation, trends.

\section{Introduction}

In order to properly prepare a team, it is necessary to act physically, technically, tactically and motivationally to learn to analyze the situations of the game and to solve them in complex conditions (Leuciuc F., 2016, p. 25-42).

In order to achieve performance in handball, efficiency is an essential part, and this largely depends on the handball player's experience and his ability to concentrate on key moments of matches (Vurgun, Dorak, Ozsaker, Uludag, 2016, p. 562-568).

Achieving sporting performance is based on the implementation of an optimal game strategy and concept, from which game models are developed and training models are tailored according to the potential of the team. Factors that determine the performance in handball are: explosive and fast actions, maximum aerobic power and speed, the ability to perform maximalefforts in situations of incomplete recovery. They must be included in the optimization process of training in high level handball game (Leuciuc F., 2012, p. 9, 24).

Nowadays, the basic characteristics of thehandball game at thelevel of senior handballteams are (Mocsai L., 2002, p. 7; Sevim
Y., Taborsky F., 2004, p. 3; Hagleitner K., 2006, p. 11; Pollany W., 2006, p. 8):

- rapidity in performing specific actions;

- dynamism in designing, implementing and completing the technical and tactical combinations;

- offensiveness and aggression in performing the game's tasks, in attack and defence;

- a high degree of technical skills of handball players that, based on an appropriate tactical reasoning, gives to the individual and collective actions a great chance of success;

-acquisition of new and spectacular technical procedures that are accessible to all players by adapting the handball learning methodology to new features;

- specialization in positions, in attack and defence, is increasingly evident with positive effects on efficiency and spectacularity of the game.

Contemporary handball obliges players to judge in every moment of the game according to a growing number of factors, demanding creative thinking in achieving the tasks of attack and defence. 


\section{Methods}

The aim of the study is to identify the specific characteristics of the handball game in the current period.

The objectives of the study are:

1. Studying the specialized literature on the topic and the analysis of the data obtained from the study of the specialized literature.

2. Developing a personal point of view regarding the approached topic and setting conclusions that will be useful in the next steps of the research.

In the study I used a series of methods that contributed to making some useful conclusions for carrying out the basic experimental research (Gagea, A., 1999, P. 222-225).

- the method of studying the specialized literature - dealing with the subject of this study, there were consulted titles by Romanian and foreign authors. Bibliography includes a significant proportion $(50 \%)$ of works in international languages, and 17 are works were publishedafter 2000. By studying the specialized literature there was also developed a systematization of information, facilitatingits analysis and use in designing and writing the scientific material.

- the comparative method - contributing to the comparison of the information on the approached topic, making it possible to formulate a proper point of view related to the addressed issues -the method of data analysis and interpretation - intended to contribute to the understanding of specific notions, of researches by other authors and to the prospecting of future research directions.

Using cumulatively these research methods, we obtaineda critical and objective analysis of the current situation regarding the addressed issues.

\section{Results and Discussions}

To achieve performance in competitions, some efficiency indicators need to be considered (Taborsky F., 2001, p.26): attack's efficiency $60 \%$; 9 m line - 40-45\%; wings - 55-60\%; central area line $6 \mathrm{~m}-60-65 \%$; counter attack- 70-75\%; $7 \mathrm{~m}$ shots - 75-80\%; attacks without shots - 15-20\%; goalkeepers $-35-40 \%$.

In a handball game there are 60-70 attack situations, of which 55-63 are completed with shots, and in turn, of these, between 30 and 40 are goals. It is also very important the manner in which the shots with scored goals end (Buchheit, M., 2003): counter attack - $11 \%$, the second phase $7 \% ; 7 \mathrm{~m}$ shots $-11 \%$, wing shots - $17 \%$, backcourt shots $-25 \%$, 6m line - $28 \%$, other types of shots $1 \%$.

In the contemporary handball game the main feature of the effort is the alternation between the large number of explosive and short actions (over 300 ) interrupted by active pause periods (up to 30 seconds). Rapid and explosive actions have an average duration of 2-3 seconds and represents about $20 \%$ of the total game time. This type of effort is an important performanceand makes the difference during a handball match (Leuciuc, 2012, p.14).

For all analysed playing positions, there were observed higher values of waist and weight for elite handball players compared to the model of specialized literature of our country, with values ranging between 4,5 and $10 \mathrm{~cm}$ for waist, respectively between 8,46 and $17,5 \mathrm{~kg}$ for weight; in all cases the difference in weight was double compared to the difference in waist. This led to a decrease in waist-100 / weight ratio below 1 , except for the wing position $-1,0004$. The value of this report clearly indicates the increase in the weight of handball players, which can be the most plausibly explained by major muscle development. The constituent aspect of handball players in the world elite denotes this (Leuciuc. F., 2008, p. 243246). Estimating the running distance by players during a game is variable depending on the playing position, as follows: wing players - 3600-4100 m, backcourt players, centerback players-2900-3500 $\mathrm{m}$, line player $-3500 \mathrm{~m}$. But the literature presents a variety of data regarding the running distance: Bon, M. (2002) - 4790 meters, Grosgeorges (1990) -4150 meters, Buchheit (2003) - 5800 $\pm 500 \mathrm{~m}$.

Usually, in the second half, due to fatigue, the players run $10 \%$ less than in the first half, respectively $55 \%$ and $45 \%$. For senior handball players the running pace, during a game, is as follows: sprints - 7\%; fast running - 25\%; moderate running - 31\%; walking - 37\% (Bon, M., 2002, p. 7).

The evolution trends of the handball game are revealed by the analyses made by professionals and researchers at the World Championships and Olympics. Knowing the development stage of the game as well as its evolutionary tendencies determines the game and training conception. Practising top level handball leads to both positive and negative trends (Ghermănescu I.K., Hnat V., 2000, p. 22; Hantău, C., 2000, p. 64; Mihăilă, I., 2006, p. 112).

Positive trends (Mocsai L., 2002, p. 8; Sevim Y., Taborsky F., 2004, p. 6; Mihăilă, I., 2006, p. 115; Hagleitner K., 2006, p. 12; Pollany W., 2006, p. 10):

- improving the technique to the level of mastery for a growing number of players and reducing the number of technical mistakes;

-increasingthe speed of the game, accompanied by a good mastery of technique and tactics, gives greater spectacular executions;

- counterattack and fastbreak are basic means for most teams;

- more and more players have mastered new and spectacular technical executions;

-defence game has become more athletic, with total physical commitment, therefore, massive, strong players are increasingly selected, able to 
perform the technical and tactical procedures in the conditions of this adversity;

individual actions are increasingly subordinated to collective game by tactical evidence for most teams;

- all world's top teams use skilfully, accurately and safely the means of collective tactics, such as: cross-actions, blocking actions, leaving the blocking actions;

-preparing the defence action of the game more carefully and rigorously, gives teams the opportunity to take initiative throughout the game, although, not being in possession of the ball, forces the attacking players to pass in a certain direction or to lose the ball without shooting;

- specialization in positions, both in attack, and in defence, is an increasingly obvious with positive effect on the effectiveness and the spectacular character of the game;

- all handball game's achievements force players to judge every moment of the game according toa growing number of factors, requiring all their capacity for reasoning.

Negative trends (Mocsai L., 2002, p. 8-9; Sevim Y., Taborsky F., 2004, p. 6; Mihăilă, I., 2006, p. 115;Hagleitner K., 2006, p. 12-13; Pollany W., 2006, p. 10):

- game without rules of the defenders, deliberately practiced;

- intentional fouls;

- brutal and deliberate attack on the ball owner with the clear purpose of hitting, injuring and intimidating him.

The increasing number of scored goals is a consequence of the increasing number of attacks, the reduction of the duration of the attack and the scored goals on counterattack;all these rely on principles of dynamic and fast pace game. To meet these requirements of current handball, players must meet the new physical, technical and tacticalrequirements, demanded by the fast and sustained pace of the game (Sevim Y., 2008, p. 1$3,31)$.

The difference in game is done by individual or small group actions and where decisional speed is essential in gaining efficiency and performance, so workouts must focus on: improving the technique and individual tactics, creating the ability to solve the 1-to-1 relationship in attack and defence; compliance with the established tactical plan; to improve collaboration on small groups (2 to 2, 3 to 3) (Táborský F., 2011, p. 9-10).

Handball players must have many motor skills allowing them to perform a varied number of technical actions, with and without ball, in a style of strength and speed,in collaboration with teammates and in opposition to the players of other teams.

Workout, technical and tactical knowledge must be applied in terms of fatigue and throughout tournaments with training matches with teams as close as possible to the competitive ones (approximate 5-8 games). According to these requirements, the positive effects will be seen in the following competitions and at the same time any errors that occur will be verified and corrected. (Leuciuc. F., 2017, p. 717-721).

\section{Conclusions}

Following the theoretical analyzes of the literary sources on the addressed regarding senior players of top level handball, the following conclusions were:

- sports performance has tremendously progressed over the past few years, performance levels hard to hit in the past have become commonplace today, and the number of players capable of outstanding performance has increased;

- considering the complexity of the players' training as a result of performance improvement, the optimization of this complex process of adapting the body to intense physical and psychological efforts, also involves organizational and medical factors that are meant to amplify the sphere, far exceeding that which is favourable to an instructive-educational process;

- handball specialists are constantly concerned with the improvement of both multi-annual and operative planning model, changing the structure, content, volume and intensity, the main aspects of top level players training; - the different approach of the players during the training is a fundamental methodological orientation in modern sports training required by the heterogeneous component of the players' groups in terms of somato-functional development and motor skills.

In order to establish the competition strategy and tactical conception of the game, the following must be taken into account (Leuciuc F., 2012, p.9):

- the features of the game practiced by the world elite handball players, being necessary to choose those essential characteristics, without which it is not possible to achieve sports performance required by the international level, but also the specific ones, which very suit the players;

- the global development trends of the game must be identified and used in training in order to have all the chances for great results in international competitions;

- capitalizing on the availability of players that can be used as trumps in confrontations with other European and international handball teams.

The handball game features in the contemporary period to be applied throughout the game and training by all the teams are: rapidity, dynamism, offensiveness, aggressiveness both in attack and defense, good technique based on tactical reasoning, which gives all the actions the chance to succeed. Based on these features, the game of handball teams must take place withhighspeed and strength, constantly moving, within the limits of accessibility and tactical utility, with the aim of increasing efficiency. They require action at a varied pace, that is, an alternation of slow actions with quick and decisive actions that will be present in all moments of the game(Leuciuc F., 2012, p. 15). More and more technicians believe that in order to eliminate the tendencies that inhibit the qualitative development of the 
game and spoil the sporting show, it is necessary to modify the rules of the game.

\section{References}

1. Bon, M. (2002).Measurement of the cyclic movements of the handball players during the game (By computer vision system (sagit)), European Handball Federation, Eurohandball Periodical, nr. 1, Vienna;

2. Buchheit, M.(2003).Bilans medicaux, epreuves d'effort en laboratoire et tests de terrain (L'exemple du Handball), http://www.martin-buchheit.net/Dossiers/M.Buchheit-

Reflexion sur l'evaluation physique et le suivi des sportifs en Handball.pdf;

3. Gagea, A. (1999).Metodologia cercetării stiințifice în educaţie fizică şi sport, Bucureşti: Fundaţiei „România de Mâine";

4. Ghermănescu, I.K., Hnat, V.(2000). Handbal I, București: Fundației „România de Mâine”;

5. Hagleitner, K.(2006).Qualitative Analysis of the 2006 Men's 20 European Handball Championship Innsbruck Austria, http://activities.

eurohandball.com/?mode $=104 \& \operatorname{ctrl}=11$

6. Hantău, C. (2000).Handbal, Buzău: Alpha;

7. Leuciuc F. (2008). Comparative study on the somatic model of the performance handball player in Romania and on the elite Handball,The Annals of "Dunarea de Jos" University of Galati, PhysicalEducationand Sport Management, 243-246;

8. Leuciuc F.(2012). Aprofundare într-o ramură sportivă: handbal, Suceava:Universității Ștefan cel Mare;

9. Leuciuc F. (2017). Longitudinal study on the effectiveness of game actions during the Olympic Games men's handball (2004-2016), Journal of Physical Education and Sport,17(2), 717 721,DOI:10.7752/jpes.2017.02108;

10. Leuciuc F., Pricop G. (2016). The longitudinal study on the effectiveness of the game actions at the World Woman's Handball Championship seniors (2005-2015), Gymnasium
Scientific Journal of Education, Sports and Health, 17(2), 25-42;

11. Mihăilă, I. (2006). Handbal - Optimizarea pregătirii fizice specifice la echipele de juniori, Craiova: Universitaria,

12. Mocsai, L. (2002). Analysing and evaluating the 2002 men's European Handball Championship, http://activities.eurohandball.com/?mode=104\&ctrl=11

13. Pollany, W. (2006). 7European Championship for men Switzerland 2006 (qualitative trend analysis), http://activities.eurohandball.com/?mode=104\&ctrl

14. Sevim Y. (2008). Handball - Dynamic Game \& Speed Training, EHF Web Periodicals, 1-3, 31, http://home.eurohandball.com/ehf_files/Publikation/WP_Se vim_Handball\%20Dynamic\%20Game $\% 20$ und $\% 20$ Speed $\%$ 20Training.pdf;

15. Sevim, Y., Taborsky, F. (2004). Qualitative trend analysis of the 6th men's European Championship Slovenia 2004, http://activities.eurohandball.com/mod

16. Taborsky F. (2001).Game performance in handball, European Handball Federation - Handball Periodical, no. 2 / 2001, AVIS-Werbung, 26,

http://home.eurohandball.com/ehf_files/Publikation/WP_C ompetitive\%20Loading\%20in\%20Top\%20Team\%20Hand ball.pdf;

17. Taborsky F. (2011).Competitive Loading in Top Team Handball and the Consequences for Training, European Handball Federation - Handball Web Periodical, 9, http://home.eurohandball.com/ehf_files/Publikation/WP_C ompetitive\%20Loading\%20in\%20Top\%20Team\%20Hand ball.pdf;

18. Vurgun N., Dorak F.R. , Ozsaker M., Uludag S. (2016). Flow Experience And Performance: A Study of Elite Turkish Handball Players, Journal of Physical Education and Sport, 16(2), 562- 568. 